\title{
Collaborations with Pediatric Hospitalists: National Surveys of Pediatric Surgeons and Orthopedic Surgeons
}

\author{
Rebecca E. Rosenberg, MD, MPH, FAAP' , Joshua M. Abzug, MD, FAAOS², David I. Rappaport, MD³, Mark V. Mazziotti, MD, \\ FACS ${ }^{4}$, M. Wade Shrader, MD, FAAOS ${ }^{5}$, David Zipes, MD ${ }^{6}$, Benedict Nwomeh, MD, FACS ${ }^{7}$ Lisa McLeod, MD, MSCE ${ }^{8}$, and the \\ AAP Section on Hospital Medicine Surgical Care Subcommittee
}

${ }^{1}$ NYU School of Medicine, New York, New York; ${ }^{2}$ University of Maryland Medical Center, Baltimore, Maryland; ${ }^{3}$ Nemours Alfred I. Dupont Hospital for Children, Wilmington, Delaware; ${ }^{4}$ Texas Children's Hospital, Houston, Texas; ${ }^{5}$ University of Mississippi, Oxford, Mississippi; ${ }^{6}$ Peyton Manning Children's Hospital, Indianapolis, Indiana; ${ }^{7}$ Nationwide Children's Hospital, Columbus, Ohio; ${ }^{8}$ Children's Hospital Colorado, Aurora, Colorado.

To understand characteristics of pediatric hospitalist (PH) involvement in the care of children admitted to surgical services and explore surgeons' perspectives of $\mathrm{PH}$ effectiveness, we conducted a cross-sectional, web-based survey of pediatric surgical (PS) and pediatric orthopedic subspecialists (OS) from professional organizations. We used basic analyses to compare responses between the two surgical groups. The initial response rate was $48 \%$ $(291 / 606)$ for PS and 59\% (415/706) for OS. Among 185 PS and 212 OS unique programs, $\mathrm{PH}$ were routinely engaged
(69\% and $75 \%)$ in the care of surgical patients, particularly in patients with medical complexity (64\% PS vs $81 \%$ OS; $P=.003)$. $P S$ and OS perceived positive $\mathrm{PH}$ impact on care coordination and comorbidity management but little on pain management or length of stay. OS were more likely than PS to view $\mathrm{PH}$ involvement positively (64\% vs $42 \%$; $P<.001)$. Further research on care models, especially for children with medical complexity, is needed. Journal of Hospital Medicine 2018;13:566-569. Published online first February 6, 2018. (C) 2018 Society of Hospital Medicine
$P$ ediatric expertise is critical in caring for children during the perioperative and postoperative periods. ${ }^{1,2}$ Some postoperative care models involve pediatric hospitalists $(\mathrm{PH})$ as collaborators for global care (comanagement), ${ }^{3}$ as consultants for specific issues, or not at all.

Single-site studies in specific pediatric surgical populations ${ }^{4-7}$ and medically fragile adults ${ }^{8}$ suggest improved outcomes for patients and systems by using hospitalist-surgeon collaboration. However, including PH in the care of surgical patients may also disrupt systems. No studies have broadly examined the clinical relationships between surgeons and $\mathrm{PH}$.

The aims of this cross-sectional survey of United States pediatric surgeons (PS) and pediatric orthopedic surgeons (OS) were to understand (1) the prevalence and characteristics of surgical care models in pediatrics, specifically those involving $\mathrm{PH}$, and (2) surgeons' perceptions of $\mathrm{PH}$ in caring for surgical patients.

\section{METHODS}

The target US surgeon population was the estimated 850 active PS and at least 600 pediatric OS. ${ }^{9}$ Most US PS $(n=606)$

\footnotetext{
*Address for correspondence: Rebecca Rosenberg, MD, MPH, 550 First Ave, New York, NY 10016; Telephone: 212-263-0959; Fax: 212-263-0557; E-mail: Rebecca.rosenberg@nyumc.org

Additional Supporting Information may be found in the online version of this article.

Received: August 1, 2017; Revised: October 11, 2017; Accepted: October 24, 2017
}

๑ 2018 Society of Hospital Medicine DOI 10.12788/jhm.2921 are affiliated with the American Academy of Pediatrics (AAP) Section on Surgery (SoSu), representing at least 200 programs. Nearly all pediatric OS belong to the Pediatric Orthopedic Society of North America (POSNA) ( $n=706)$, representing 340 programs; a subset $(n=130)$ also belong to the AAP SoSu.

\section{Survey Development and Distribution}

Survey questions were developed to elicit surgeons' descriptions of their program structure and their perceptions of $\mathrm{PH}$ involvement. For programs with $\mathrm{PH}$ involvement, program variables included primary assignment of clinical responsibilities by service line (surgery, hospitalist, shared) and use of a written service agreement, which defines each service's roles and responsibilities.

The web-based survey, created by using Survey Monkey (San Mateo, California), was pilot tested for usability and clarity among eight surgeons and one $\mathrm{PH}$. The survey had logic points around involvement of hospitalists and multiple hospital affiliations (supplemental Appendix A). The survey request with a web-based link was e-mailed three times to surgical and orthopedic distribution outlets, endorsed by organizational leadership. Respondents' hospital ZIP codes were used as a proxy for program. If there was more than one complete survey response per ZIP code, one response with complete data was randomly selected to ensure a unique entry per program.

\section{Classification of Care Models}

Each surgical program was classified into one of the following three categories based on reported care of primary surgical patients: (1) comanagement, described as $\mathrm{PH}$ writing orders and/ 
TABLE. Survey Responses Grouped by Hospitals and by Individual Surgeons

\begin{tabular}{|c|c|c|c|}
\hline HOSPITAL PROGRAMS & $\begin{array}{c}\text { Pediatric General Surgery } \\
\text { Programs }\end{array}$ & $\begin{array}{l}\text { Pediatric Orthopedic } \\
\text { Programs }\end{array}$ & $\begin{array}{c}P \text { value, } \\
\chi^{2}\end{array}$ \\
\hline Total & 185 & 212 & \\
\hline Primary site & 145 & 171 & \\
\hline Secondary site & 40 & 41 & \\
\hline Number of pediatric beds ${ }^{\mathrm{a}}$ & & & $<.001$ \\
\hline$<60$ & $14(10 \%)$ & $50(26 \%)$ & \\
\hline $61-100$ & $19(13 \%)$ & $31(16 \%)$ & \\
\hline $101-200$ & $43(30 \%)$ & $39(20 \%)$ & \\
\hline$>200$ & $65(45 \%)$ & $73(38 \%)$ & \\
\hline \multicolumn{4}{|l|}{ Hospital type } \\
\hline Freestanding & $93(50 \%)$ & $117(55 \%)$ & .340 \\
\hline $\mathrm{CH}$ within general & $54(29 \%)$ & $50(24 \%)$ & \\
\hline General tertiary/no $\mathrm{CH}$ & $24(13 \%)$ & $22(10 \%)$ & \\
\hline Community/other & $14(8 \%)$ & $23(11 \%)$ & \\
\hline \multicolumn{4}{|l|}{ Primary team includes } \\
\hline Surgical residents & $181(98 \%)$ & $180(85 \%)$ & $<.001$ \\
\hline Surgical advanced providers & $168(91 \%)$ & $136(64 \%)$ & $<.001$ \\
\hline Type of PH involvement ${ }^{\mathrm{a}}$ & & & $<.001$ \\
\hline No involvement & $49(28 \%)$ & $43(21 \%)$ & \\
\hline PH involvement & $127(69 \%)$ & $158(75 \%)$ & \\
\hline Follows/no orders (consult) & $54(31 \%)$ & $20(10 \%)$ & \\
\hline Follows/writes orders (comanage) & $73(42 \%)$ & $138(69 \%)$ & \\
\hline \multicolumn{4}{|l|}{ SURGEONS } \\
\hline Unique respondents & 252 & 340 & ns \\
\hline Posttraining $>10$ years & $158(66 \%)$ & $259(69 \%)$ & \\
\hline$>75 \%$ practice children $<18$ years old & $240(92 \%)$ & $228(95 \%)$ & \\
\hline
\end{tabular}

Primary hospitals.

NOTE: Data may not add up to $100 \%$ because of incomplete or inconsistent answers.

Abbreviations: $\mathrm{CH}$, Children's Hospital; ns, not significant; $\mathrm{PH}$, pediatric hospitalist.

or functioning as the primary service; (2) consultation, described as $\mathrm{PH}$ providing clinical recommendations only; and (3) no $\mathrm{PH}$ involvement, described as "rarely" or "never" involving PH.

\section{Clinical Responsibility Score}

To estimate the degree of hospitalist involvement, we devised and calculated a composite score of service responsibilities for each program. This score involved the following seven clinical domains: management of fluids or nutrition, pain, comorbidities, antibiotics, medication dosing, wound care, and discharge planning. Scores were summed for each domain: 0 for surgical team primary responsibility, 1 for shared surgical and hospitalist responsibility, and 2 for hospitalist primary responsibility. Composite scores could range from 0 to 14; lower scores represented a stronger tendency for surgeon management, and higher scores represented a stronger tendency toward PH management.

\section{Data Analysis}

For data analysis, simple exploratory tests with $\chi^{2}$ analysis and Student $t$ tests were performed by using Stata 14.2 (StataCorp LLC, College Station, Texas) to compare differences by surgi- cal specialty programs and individuals by role assignment and perceptions of PH involvement.

The NYU School of Medicine Institutional Review Board approved this study.

\section{RESULTS}

\section{Respondents and Programs}

Of the estimated 606 PS in the AAP SoSu, 291 (49\%) US-based surgeons (PS) responded with 251 (41\%) sufficiently completed surveys (Table). The initial and completed survey response rate for pediatric OS through the POSNA listserv was $58 \%$ and $48 \%$ (340/706), respectively. These respondents represented 185 unique PS programs and 212/340 (62\%) unique OS programs in the US (supplemental Appendix B).

Among the unique 185 PS programs and 212 OS programs represented, $\mathrm{PH}$ were often engaged in the care of primary surgical patients (Table).

\section{Roles of PH in Collaborative Programs}

Among programs that reported any hospitalist involvement (PS, $n=100 ;$ OS, $n=157)$, few ( $\leq 15 \%)$ programs involved hospitalists 


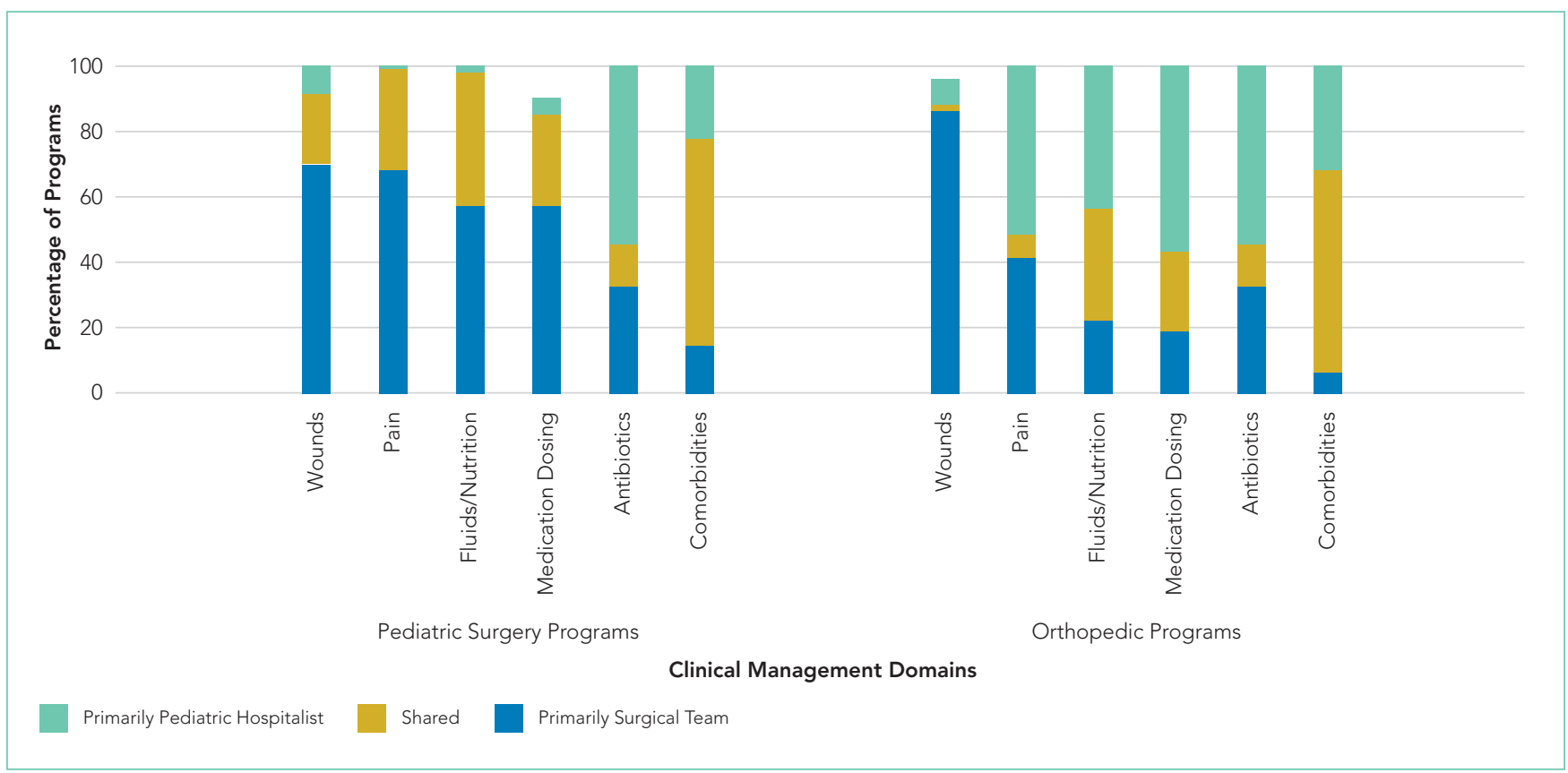

FIG 1. Distribution of clinical domain management among pediatric surgery $(n=100)$ and orthopedic surgery programs ( $n=157)$ by clinical team responsibility: primarily surgical, hospitalist, or shared.

with all patients. Pediatric OS programs were significantly more likely than pediatric surgical programs to involve $\mathrm{PH}$ for healthy patients with any high-risk surgery $(27 \%$ vs $9 \% ; P=.001)$. Most PS (64\%) and OS (83\%) reported involving $\mathrm{PH}$ for all medically complex patients, regardless of surgery risk $(P=.003)$.

In programs involving $\mathrm{PH}$, few PS (11\%) or OS programs (16\%) reported using a written service agreement.

\section{Care of Surgical Patients in PH-involved programs}

Both PS and OS programs with hospitalist involvement reported that surgical teams were either primarily responsible for, or shared with the hospitalist, most aspects of patient care, including medication dosing, nutrition, and fluids (Figure). PH management of antibiotic and nonsurgical comorbidities was higher for OS programs than PS programs.

Composite clinical responsibility scores ranged from 0 to 8 , with a median score of 2.3 (interquartile range [IQR] 0-3) for consultation programs and 5 (IQR 1-7) for comanagement programs. Composite scores were higher for OS (7.4; SD 3.4) versus PS (3.3; SD 3.4) programs ( $P<.001$; 95\% Cl, 3.3-5.5; supplemental Appendix C).

\section{Surgeons' Perspectives on Hospitalist Involvement} Surgeons in programs without $\mathrm{PH}$ involvement viewed $\mathrm{PH}$ overall impact less positively than those with $\mathrm{PH}$ (27\% vs 58\%). Among all surgeons surveyed, few perceived positive (agree/ strongly agree) $\mathrm{PH}$ impact on pain management $(<15 \%)$ or decreasing LOS ( $\leq 15 \%$; supplemental Appendix D).

Most surgeons $(n=355)$ believed that $\mathrm{PH}$ financial support should come from separate billing (patient fee; 48\%) or hospital budget (36\%). Only $17 \%$ endorsed $\mathrm{PH}$ receiving part of the surgical global fee, with no significant difference by surgical specialty or current $\mathrm{PH}$ involvement status.

\section{DISCUSSION}

This study is the first comprehensive assessment of surgeons' perspectives on the involvement and effectiveness of $\mathrm{PH}$ in the postoperative care of children undergoing inpatient general or orthopedic surgeries. The high prevalence $(>70 \%)$ of $\mathrm{PH}$ involvement among responding surgical programs suggests that $\mathrm{PH}$ comanagement of hospitalized patients merits attention from providers, systems, educators, and payors.

\section{Collaboration and Roles are Correlated with Surgical Specialty and Setting}

Forty percent of inpatient pediatric surgeries occur outside of children's hospitals. ${ }^{10}$ We found that $\mathrm{PH}$ involvement was higher at smaller and general hospitals where $\mathrm{PH}$ may provide pediatric expertise when insufficient pediatric resources, like pain teams, exist. ${ }^{7}$ Alternately, some quaternary centers have dedicated surgical hospitalists. The extensive involvement of $\mathrm{PH}$ in the bulk of certain clinical care domains, especially care coordination, in OS and in many PS programs (Figure) suggests that $\mathrm{PH}$ are well integrated into many programs and provide essential clinical care.

In many large freestanding children's hospitals, though, surgical teams may have sufficient depth and breadth to manage most aspects of care. There may be an exception for care coordination of medically complex patients. Care coordination is a patient- and family-centered care best practice, ${ }^{11}$ encompasses integrating and aligning medical care among clinical services, and is focused on shared decision making and communication. High-quality care coordination processes are of great value to patients and families, especially in medically complex children, ${ }^{11}$ and are associated with improved transitions from hospital to home. ${ }^{12}$ Well-planned transitions likely decrease 
these special populations' postoperative readmission risk, complications, and prolonged length of stay. ${ }^{13}$ Reimbursement for these services could integrate these contributions needed for safe and patient-centered pediatric inpatient surgical care.

\section{Perceptions of PH Impact}

The variation in perception of $\mathrm{PH}$ by surgical specialty, with higher prevalence as well as higher regard for $\mathrm{PH}$ among OS, is intriguing. This disparity may reflect current training and clinical expectations of each surgical specialty, with larger emphasis on medical management for surgical compared with orthopedic curricula (www.acgme.org).

While PS and OS respondents perceived that $\mathrm{PH}$ involvement did not influence length of stay, pain management, and resource use, single-site studies suggest otherwise. ${ }^{4,8,14}$ Objective data on the impact of $\mathrm{PH}$ involvement on patient and systems outcomes may help elucidate whether this is a perceived or actual lack of impact. Future metrics might include pain scores, patient centered care measures on communication and coordination, patient complaints and/or lawsuits, resource utilization and/or cost, readmission, and medical errors.

This study has several limitations. There is likely a (self) selection bias by surgeons with either strongly positive or negative views of PH involvement. Future studies may target a random sampling of programs rather than a cross-sectional survey of individual providers. Relatively few respondents represent-

\section{References}

1. Task Force for Children's Surgical Care. Optimal resources for children's surgical care in the United States. J Am Coll Surg. 2014;218(3):479-487, 487.e1-4.

2. Section on Hospital Medicine, American Academy of Pediatrics. Guiding principles for pediatric hospital medicine programs. Pediatrics. 2013;132(4):782-786

3. Freiburg C, James T, Ashikaga T, Moalem J, Cherr G. Strategies to accommodate resident work-hour restrictions: Impact on surgical education. J Surg Educ. 2011;68(5):387-392.

4. Pressel DM, Rappaport DI, Watson N. Nurses' assessment of pediatric physicians: Are hospitalists different? J Healthc Manag. 2008;53(1):14-24; discussion 24-25.

5. Simon TD, Eilert R, Dickinson LM, Kempe A, Benefield E, Berman S. Pediatric hospitalist comanagement of spinal fusion surgery patients. J Hosp Med. 2007;2(1):23-30.

6. Rosenberg RE, Ardalan K, Wong W, et al. Postoperative spinal fusion care in pediatric patients: Co-management decreases length of stay. Bull Hosp Jt Dis (2013). 2014;72(3):197-203.

7. Dua K, McAvoy WC, Klaus SA, Rappaport DI, Rosenberg RE, Abzug JM. Hospitalist co-management of pediatric orthopaedic surgical patients at a community hospital. Md Med. 2016;17(1):34-36.

8. Rohatgi N, Loftus P, Grujic O, Cullen M, Hopkins J, Ahuja N. Surgical comanagement by hospitalists improves patient outcomes: A propensity ed community hospitals, possibly because these facilities are staffed by general OS and general surgeons ${ }^{10}$ who were not included in this sample.

\section{CONCLUSION}

Given the high prevalence of $\mathrm{PH}$ involvement in caring for surgical pediatric patients in varied settings, the field of pediatric hospital medicine should support increased $\mathrm{PH}$ training and standardized practice around perioperative management, particularly for medically complex patients with increased care coordination needs. Surgical comanagement, including interdisciplinary communication skills, deserves inclusion as a $\mathrm{PH}$ core competency and as an entrustable professional activity for pediatric hospital medicine and pediatric graduate medical education programs, ${ }^{15}$ especially orthopedic surgeries.

Further research on effective and evidence-based pediatric postoperative care and collaboration models will help $\mathrm{PH}$ and surgeons to most effectively and respectfully partner to improve care.

\section{Acknowledgments}

The authors thank the members of the AAP Section on Hospital Medicine Surgical Care Subcommittee, AAP SOHM leadership, and Ms. Alexandra Case.

Disclosure: The authors have no conflicts of interest relevant to this manuscript to report.

Funding: This study was supported in part by the Agency for Health Care Research and Quality (LM, ROOHSO22198).

score analysis. Ann Surg. 2016;264(2):275-282.

9. Poley S, Ricketts T, Belsky D, Gaul K. Pediatric surgeons: Subspecialists increase faster than generalists. Bull Amer Coll Surg. 2010;95(10):36-39.

10. Somme S, Bronsert M, Morrato E, Ziegler M. Frequency and variety of inpatient pediatric surgical procedures in the United States. Pediatrics. 2013;132(6):e1466-e1472.

11. Frampton SB, Guastello S, Hoy L, Naylor M, Sheridan S, Johnston-Fleece $M$, eds. Harnessing Evidence and Experience to Change Culture: A Guiding Framework for Patient and Family Engaged Care. Washington, DC: National Academies of Medicine; 2017.

12. Auger KA, Kenyon CC, Feudtner C, Davis MM. Pediatric hospital discharge interventions to reduce subsequent utilization: A systematic review. J Hosp Med. 2014;9(4):251-260.

13. Simon TD, Berry J, Feudtner $C$, et al. Children with complex chronic conditions in inpatient hospital settings in the united states. Pediatrics. 2010;126(4):647-655.

14. Rappaport DI, Adelizzi-Delany J, Rogers KJ, et al. Outcomes and costs associated with hospitalist comanagement of medically complex children undergoing spinal fusion surgery. Hosp Pediatr. 2013;3(3):233-241.

15. Jerardi K, Meier K, Shaughnessy E. Management of postoperative pediatric patients. MedEdPORTAL. 2015;11:10241. doi:10.15766/mep_23748265.10241. 